\title{
The Design and Implementation of Cloud Computing Network Teaching Platform
}

\author{
Shangyou Ju \\ Ningbo City College of Vocational Technology
}

\begin{abstract}
Along with the constant economic improvement and development in China, information technology has been rapidly developed and applied. All fields are inseparable from the support of information technology. Cloud computing technology is derived and developing from information technology. How to make the information-based education construction keep pace with the development of the times and meet the demand of education workers for technology has been the focus of the education department. In this paper, cloud computing network teaching platform design method is raised and a comprehensive teaching evaluation system combining access, integration, and management is established so as to implement autonomous learning and remote teaching. In this paper, the platform framework is analyzed and studied in depth. The cloud computing network teaching system project is complex, and therefore, the platform construction method and operating model are necessarily studied deeply.
\end{abstract}

Keywords- Cloud Computing; Network Teaching; Platform Design; Study

\section{Introduction}

The focus of information construction is on product allocation and universal coverage, and then can be smoothly transitioned to the integration and optimal utilization of curriculum resources and the development and utilization of information resources, for the ultimate goal of improving the teaching service quality. How to use the limited funds to promote the education information to keep pace with the development of the times and better meet the needs of teaching workers becomes a concern for education department. Under normal circumstances, college students give top priority to self-study, but often encounter all sorts of problems. Moreover, the shortage of global resources and the environmental degradation are very serious. For all these reasons, it is very urgent to establish a complete network teaching platform and a contingency plan. Cloud computing network teaching platform can integrate design and research together to meet the needs of the educational worker; the integration of many most advanced technologies is essentially to integrate and optimally utilize the information resources.

\section{The architecture design of cloud computing network teaching platform}

The cloud computing network teaching platform design is based on cloud computing technology; a unified portal website is constructed to integrate education management platform, teaching resources management system, and remote teaching evaluation system together, and it is divided into five top-to-bottom layers (i.e. the layer of knowledge presentation, the layer of core applications, the layer of management, the layer of architecture, and the layer of IT resources). The system function modules are as follows.

\subsection{The layer of knowledge presentation}

The layer of knowledge presentation in the system can reflect the portal system, and it is designed and planed by combining with the integral platform design style and the local characteristics; students are classed as portals and teachers are as sub-portals, followed by families and campus sub-portals. All these 
portals and sub-portals are in common operation, management and collaboration. In student portals, class hour selection, classroom questioning, examination, and learning software downloads are available to use and also can be connected and implemented uniformly. Teachers can better complete teaching plans, course arrangement, online answer, teaching evaluation, training, and lesson preparation in the sub-portals design and use these functions together. School and family interactive portal is convenient for parents and teachers, so they can interact with students very fast by logging in the portal website and also discuss some problems with students; teachers can release information and notice with the aid of the portal website. The operation and management portal provides maintenance and operational management related functions such as software updates, download, condition based maintenance, troubleshooting, backend maintenance, and security backup [1].

\subsection{The layer of core applications}

In the layer of core applications, the contents of the layer of knowledge presentation are used as supports and platform system centers; all tasks such as teaching management, teaching task implementation, teaching evaluation, and teaching plan making are completed; a closed-loop management process is built by integrating the center contents to specifically show the specific practice and also implement the basic functions such as online learning, network library, network laboratory, database, repository, and search engines. Its function description is as follows: user management, account management; student management, administrator management [2]; operation management, including background operation, and maintenance personnel management and so on.

\subsection{The layer of cloud platform operation management}

The layer of cloud platform operation management is a carrier of the functions of operation management sub-portal, and its main functions include resources integration and scheduling, system monitoring, performance management, security management, and content audit, deleting ineligible contents, and backup management and accounting management. This layer relies on independent development, and its technical requirements are high, so supports from professional personnel or the third party software are required.

\subsection{The layer of cloud platform infrastructure}

The layer of cloud platform infrastructure mainly provides four basic functions: Infrastructure function, development and test function, deployment and operation function, and operation management function. Infrastructure function mainly includes file subsystem, parallel task scheduling subsystem, and distributed programming interface subsystem [3]. SDK development kit control is very strict. To enable developers to directly distribute the product to the Internet, cloud computing network teaching platform is the only support for the maintenance and certification. This is an important method to secure the plans of the developers not to be reproduced and stolen, and can protect the intellectual property. Meanwhile, it can ensure the programs not to fail and invade and affect the entire platform system; deployment errors will not affect the whole platform function. Deployment development function can also be applied to packaging, application certification, deployment, and custody and operation. In operational management, the identity of developers is necessarily certificated; the available functions include storage, platform monitoring, billing, settlement management, platform security, access control, and statistics; developers is strictly reviewed and also a credit certificate is issued for them when the identity of administrators is authenticated. In the platform infrastructure layer as the center and core of the whole platform, the most advanced technologies are applied, which can be only used in 
professional companies such as Google App Engine (GAE) and Baihui cloud computing service platform (Baihui.com), and Apache Hadoop operational platform. The platform infrastructure layer involves many core technologies. Parallel computer also involves the task decomposition, communication, combination and mapping, and also decomposes itself, considers parallel models, and views the network connection.

\subsection{The layer of IT resources}

The layer of IT resources includes two sublayers: the physical resource management sublayer and the virtualization resources sublayer. The physical resource management sublayer includes network, storage, and host. The virtualization resources sublayer includes the virtualization of the physical resource management sublayer, the formation of the storage resource pool and network resource pool, the optimization, integration and management of resources in resource pools, and easier allocation, recycling and utilization of resource dynamics. The layer of IT resources also involves many key technologies, in which virtualization is a very important technology and can hidden the complexity and heterogeneity of IT infrastructure. Thus, users are needless to know well the specific positions of server, network, and storage. Virtual network is essentially a logic relation and very little restricted physically [4].

\section{Cloud computing network teaching platform construction and operational model analysis}

By Platform function architecture design and analysis, a cloud computing network teaching platform can be established. It is a complicated system project and needs the construction of perfect implementation strategies, so as to build a complete platform using the limited funds. Usually, there are three kinds of construction and operation models to choose.

\subsection{The construction and operation dominated by the education system}

The education system includes electrified education bureau, education bureau, and school departments. These departments are dominant in the operation. In the education system, operational management and risk pre-control can be implemented; electrified education bureau is closely linked with school information technology; with the professional training, the system operation will be more efficient with the aid of school cloud computing emergence teaching platform construction. The advantage of this model lies in connecting with the education system and controlling the entire platform. That is to say, it possesses the dominant right. But the application of this model lacks professional skills and faculty supports, and also its operational experience is not enough so that unhealthy supervision is caused.

\subsection{The construction and operation dominated by the third party company}

The model is dominated by the third party, but the supervision on the third party company is absent and professional supervision tools and means are not applied, so that start-up capital increases for the model and the establishment of the platform is hard to begin within the shortest time. Therefore, enough money support is required and also the third party company needs abundant capital to maintain.

\subsection{The construction and operation dominated jointly by the education system and the third party company}

The model is dominated jointly by the education system and the third party company. That is to say, the construction is dominated by the two sides. From the theory analysis, it is a sharing, cooperative model, in which the elements are respectively responsible for the contents of construction and operation, learn from each other, and complement each other, aiming to promote the model to be optimized and utilized. The 
education system also provides different business needs, emphatically focuses on the personnel training, and supervises the whole system; a professional company is responsible for technology and personnel training and the maintenance and construction of the platform.

\section{The evolution of cloud computing network teaching platform}

The implementation of cloud computing network teaching platform needs the construction and implementation of teaching resource pool and also construction of application support platform. The key of the construction of the application support platform lies in meeting the teaching demand and also rigorously analyzing this demand - the structure of the technology platform is adjusted and optimized so as to promote it to be more stable and reasonable. Education departments can arrange teaching investigation and research and collect opinions, and accordingly draw lessons from other colleges and universities, and establish a cloud computing network platform in combination with the practical problems such as resource type, quantity and structure. Second, under the cloud computing model, the computer performance will be greatly reduced and the computer function is expanded; in order to share the resources and increase the resources utilization rate, the teaching information and resources are classified and induced and then the resource allocation becomes more reasonable and scientific. After the network teaching platform's function and structure are stabilized, the technology platform function and structure are deeply developed, or new technology or network platform is introduced. Teaching resource is the foundation and core of the network teaching platform, and thus, the network teaching platform under the cloud computing model needs the supports from teaching resource pool [5].

\section{Conclusion}

With the rapid development of information technology, cloud computing technology will be better-improved and mature, and also will be more commonly applied to different fields. A close combination of cloud computing technology with the education is an inevitable requirement of the educational development and conforms to the actual teaching demand. Network teaching platform is an important exploration of cloud computing model and its application promotes the network teaching management to be more convenient. As a result, the teaching management level is enhanced; the teaching resources are fully utilized. The network platform under the cloud computing model can mobilize students' initiative in autonomous learning; teachers can faster and timely acquire the learning conditions of students. Anyway, cloud computing network teaching platform plays a promoting role in education and is worthy of research and extension.

\section{References}

[1] Jun Du. The Design and Implementation of Adult Education Courses Tutorial under the Cloud Computing Environment-"Instructional Design" Course Is Taken for Example [J]. Journal of State Forestry Administration Management Cadre Institute, 2010, 09 (3): 49-51.

[2] Jingye Qu, Ruibin Liang. Study on the Construction of the Network Teaching Platform Information Ecosystem based on cloud Computing [J]. Journal of Information Science and Technology, 2014 (28): 167-167.

[3] Lili Liu. Study on the Development of the College Network Teaching Platform Based on Cloud Computing [J]. Journal of Taiyuan Vocational and Technical College, 2014 (4): 174-175. 
[4] Jingyun Liu. The Application and Implementation of Cloud Computing Technology in the Network Teaching Platform Design [J]. Journal of Electronic Test, 2014 (Z1): 152-153, 159.
[5] Fang Peng. The Reform of School-enterprise Cooperation Personnel Training in "Cloud Model" Computer Program [J]. Journal of Network Security Technology and Applications, 2014 (12): 164, 166. 